
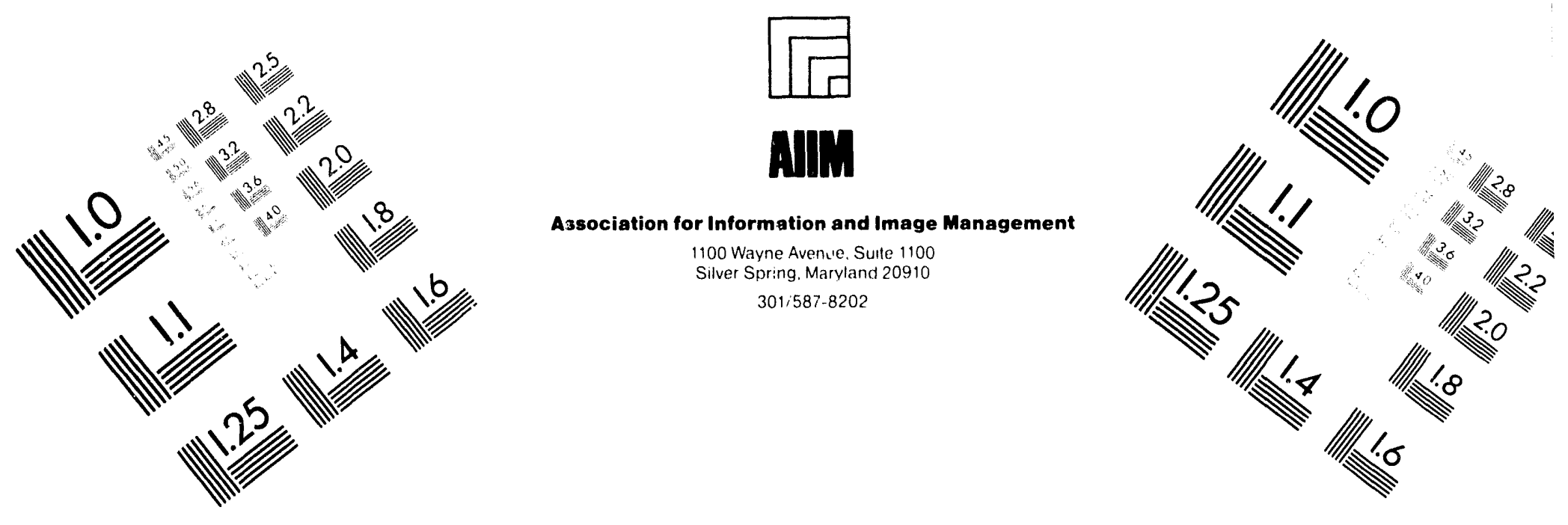

\title{
Centimeter
}

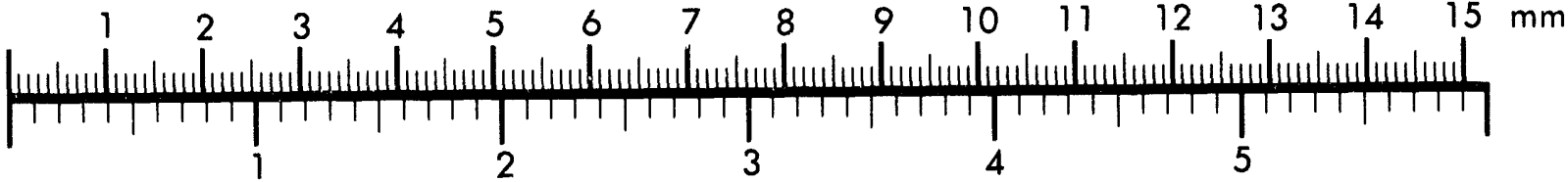

Inches
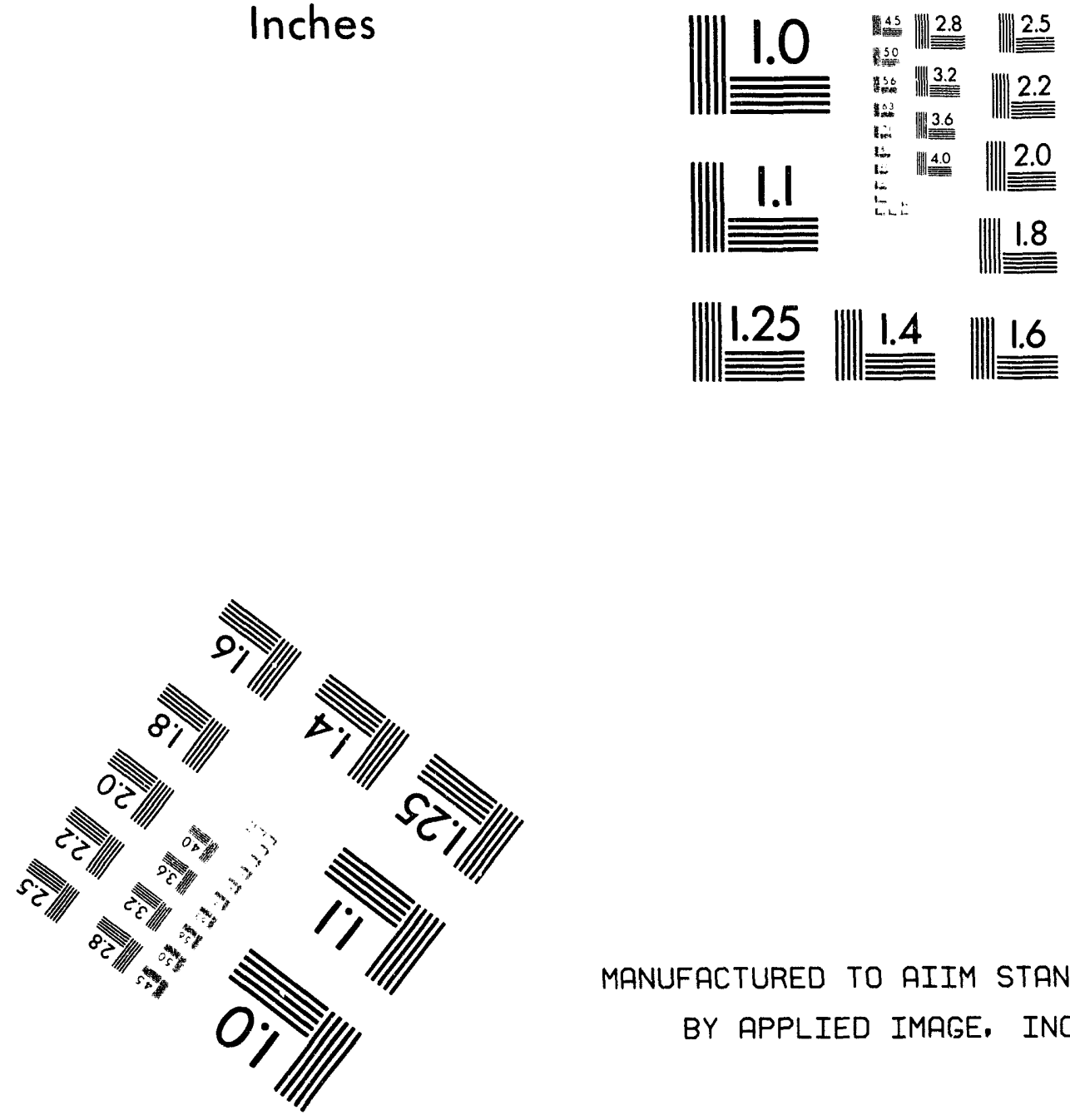

MANUFACTURED TO AIIM STANDARDS

BY APPLIED IMAGE, INC.

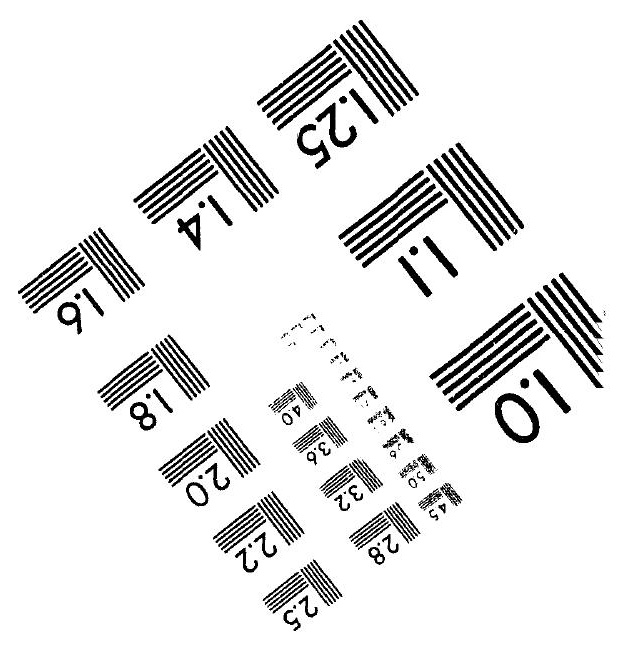



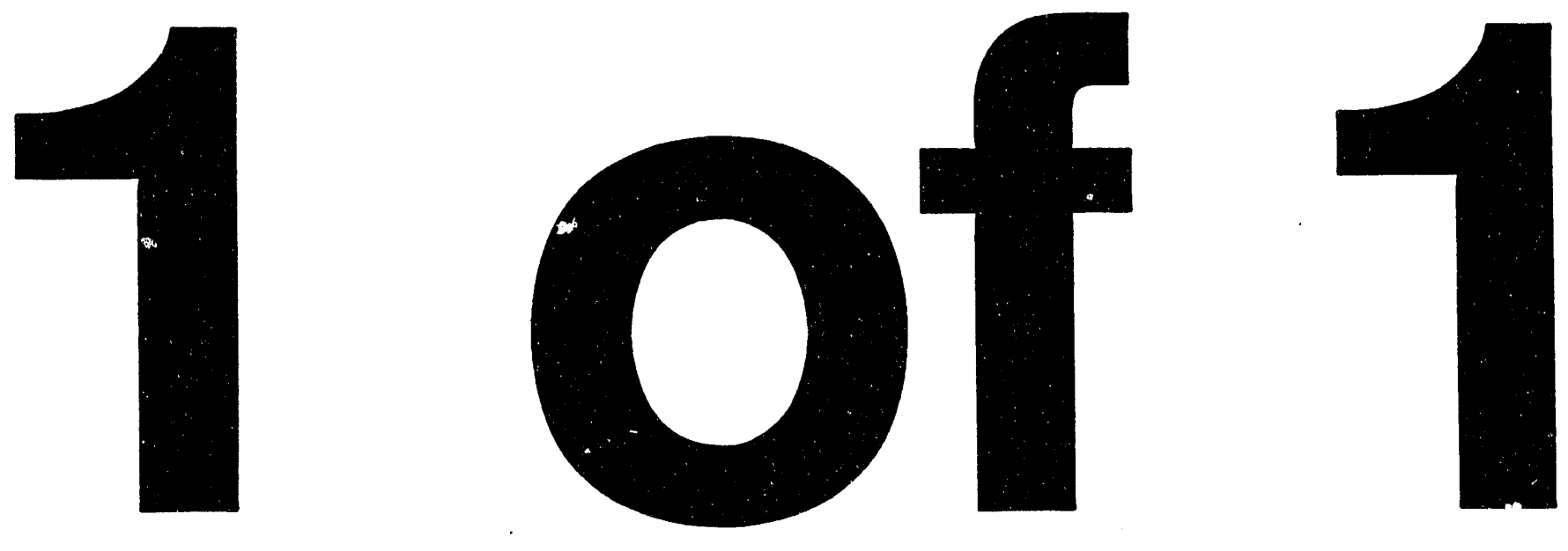
WSRC-RP-93-1376

\section{Dismantlement and Decontamination of a Plutonium-238 Facility at SRS (U)}

Authors:

R. H. Smith, Jr.

H. E. Hootman

Approved by:

T. H. Gould, Manager

Strategic Planning and Analysis

January 1994

Westinghouse Savannah River Company

Savannah River Site

Aiken, SC 29808

Prepared for the U. S. Department of Energy under Contract No. DE-AC09-89SR18035

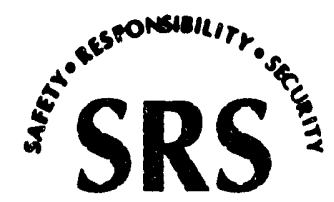

SAVANNAH RIVER SITE

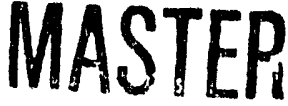




\section{Disclaimer}

This report was prepared as an account of work sponsored by an agency of the United States Government. Neither the United States Government nor any agency thereof, nor any of their employees, makes any warranty, express or implied, or assumes any legal liability or responsibility for the accuracy, completeness, or usefulness of any information apparatus, produce, or process disclosed, or represents that its use would not intringe privately owned rights. Reference herein to any specific commercial product, process, or service by trade name, trademark, manufacturer, or otherwise does not necessarily constitute or imply its endorsement, recommendation, or favoring by the United States Government or any agency thereof. The views and opinions of authors expressed herein do not necessarily state or reflect those of the United States Government or any agency thereof.

\section{Published in Cooperation with WSRC Management Services} Department Publications Group.

Technical Editor: Charlie Tope 
WSRC-RP-93-1376

Publication Date: 1/94

\section{Dismantlement and Decontamination of a Plutonium-238 Facility at SRS (U)}

Authors:

R. H. Smith, Jr.

H. E. Hootman

Approved by:

T. H. Gould, Manager

Strategic Planning and Analysis

January 1994

Westinghouse Savannah River Company

Savannah River Site

Aiken, SC 29808

Prepared for the U. S. Department of Energy under Contract No. DE-AC09-89SR18035

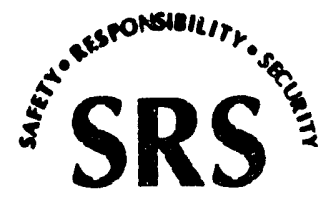


This page intentionally left blank. 


\section{Introduction}

\section{Summary}

There has been very little documented decontamination and decommissioning (D\&D) experience on which to project cleanup costs and schedules for plutonium facilities at SRS and other DOE sites. A portion of the HB-Line, a plutonium-238 processing facility at SRS, has been undergoing D\&D intermittently since 1984 . Although this cleanup effort was not originally intended to quantify results, some kev data have been accumulated, and the project has demonstrated effective methods of performing D\&D work, and has demonstrated cleanup equipment and techniques under conditions of high contamination.

Plutonium facilities where D\&D is already underway provide an opportunity for timely field testing of characterization, size reduction, and decontamination techniques. Some data are presented here; however, more specific tests and data may be obtained during the remainder of this project. This project has been recommended as a candidate test facility for a DOE planned "Integrated D\&D Demonstration" managed by EM-50 to develop and demonstrate technology for D\&D and surplus facilities deactivation. Both the remainder of this project and the Integrated D\&D Demonstration Program can benefit from a joint effort, and the overall costs should be reduced.

The HB-Line operated from 1963 to 1984 producing radioisotopic heat source plutonium-238 material for NASA programs. The facility cleanup effort begun in 1984 combines the challenge of high radiation, very high contamination, cramped quarters, and coexistence with an operating facility. The process areas were highly contaminated with plutonium, which is extremely toxic when inhaled. For personnel protection, processing equipment was contained in gloveboxes or cabinets with controlled ventilation. The facility is located within the currently active fuel reprocessing canyon building $221-\mathrm{H}$, in $\mathrm{H}$-Aren at SRS. The current status of this project is that half of the $10,000 \mathrm{sq} f$ facility area has been cleaned, and the remainder is scheduled to be cleaned up in the next three years.

Excluding the eventual solid waste processing cost, the project has cost about 12.5 million dollars to completely D\&D approximately 5000 square feet of floor area of the plutonium facility, or $\$ 2500$ per square foot of plutonium facility. Although the elapsed time for the cleanup has been 9 years, the effort was intermittent; and it is estimated it would have required the equivalent of about five years of continuous effort.

Approximately $213,000 \mathrm{cu} f \mathrm{ft}$ of solid waste was generated, equivalent to about $43 \mathrm{cu}$ ft of waste per square foot of empty facility floor area. This basis was chosen because most plutonium facilities require a comparable operating and maintenance area to support the enclosed processes. Another way to express $D \& D$ waste generation is to divide the total waste volume from D\&D by the original equipment volume, which results, in this case, in a factor of 109 increase. About 50 percent of the waste generated was transuranic (TRU) waste; the remainder was low-level waste (LLW). Less than $500 \mathrm{cu} f t$ of mixed waste was generated, and consists primarily of lead shielding. The amount of liquid decontamination waste generated to date is unavailable because the contaminated wash water was pumped to the adjacent canyon for 
evaporation and transfer to the area waste tanks. This information is now being documented for future reference.

Data reported here should provide an upper limit for plutonium facility D\&D waste generation, cleanup time, and cost. This project required more decontamination time and generated twice the job control waste of a typical plutonium facility because of the high contamination levels due to the higher specific activity of Pu-238. Comparing moderately-aged isotopic mixtures, $\mathrm{Pu}-238$ is a factor of about 30 times more radioactive per gram than Pu-239. Criticality concerns are greater in facilities that have processed more fissile materials, and may prohibit D\&D methods involving hydrogenous decontaminants. Considerable differences will also exist in the risk and costs of waste treatment and disposal because of different facility locations with respect to liquid and solid waste handling facilities. In general, risks with regard to worker safety are greater for D\&D than for routine production activities.

\section{Discussion}

Facility Description

Initial Planning
The HB-Line facility was designed to receive radionuclides in dilute acid solutions from the fuel reprocessing canyon, precipitate them as oxalates, and then calcine them in a furnace to a free flowing oxide form. To accomplish these steps, the facility contained both shielded and unshielded tanks, transfer lines, glovebox enclosed precipitation and furnace stations, material transfer, and waste treatment and packaging stations. The facility processed neptunium-237, plutonium-239, uranium-233 \& 235 as well as plutonium238. Over the lifetime of the facility, supplemental shielding was added to reduce operating personnel radiation exposure. The portion of the HB-Line that was cleaned up is illustrated in Figure 1.

Normally in decommissioning, options are assessed on whether to remove the equipment or leave it in place. In this instance, the facility was within the fuel reprocessing canyon building, and potential risk to personnel justified removal. In 1989 , a portion of the $221-\mathrm{H}$ facility including a part of the old HB-Line, was chosen as the location for the Uranium Solidification Facility. Careful and detailed planning was required to control risk, costs, and exposure because total $D \& D$ of the plutonium facility contents was required to enable construction of a new facility. The rnethods of D\&D resulted from continued analysis of the risk, costs, regulatory requirements, and engineering feasibility.

The work in each process area was planned to be accomplished in logical phases to minimize the spread of radioactive contamination. A typical plan is shown in Table 1. First, all noncontaminated equipment was to be removed. All lines and service piping were physically identified, traced, and flushed. At this time, an extensive set of photographs was taken for reference and for pre-entry briefings during future dismantlement operations. The next step was emptying and cleaning the process cabinets. In the contaminated cabinet cleanup, the interiors were decontaminated to a practical limit (established by the D\&D team) and then painted to fix transferable contamination. Cabinet ventilation was kept in service until dismantlement was completed. During cabinet removal, each cabinet (or glovebox) was separated from adjoining 
cabinets, sectioned if too large for safe handling, and packaged according to shipping requirements. Measures such as fixation, bagging, or the use of temporary enclosures were required at all severance points to maintain contamination control. Finally, the vacated areas were decontaminated to as low a level of radioactivity as economically practicable. The walls were painted, floors were retiled, and the rooms were provided with a minimum of required services such as lights, ventilation, and alarms.

This project benefited from available resources including trained personnel familiar with the facility, active ventilation systems, and radioactive liquid disposal facilities within the fuel processing building. Initially, an attempt was made to perform a detailed task analyses; however, it soon became apparent that there is no generic approach to facilitate D\&D. Each process area has its own unique problems that required specific task analyses and procedures for accomplishment. Specific work procedures were found effective for only limited task objectives after thorough radiological and safety surveys.

D\&D Considerations

Because of high background radiation in the Neptunium and Scrap Recovery Lines, all noncontaminated equipment could not be removed before the cabinets were breached to remove radioactive residues. Subsequent efforts focused on locating and removing the identifiable sources of radiation dose to the workers. In planning the removal of radioactive sources, one must decide how ALARA goals are best served. In some cases, a high dose to a few workers for the short time of source removal can offset higher accumulated doses to many workers over an extended period of time. The most intense source was a thermally hot, dry residue buildup in the bottom of one of the process cabinets. Supplementary shielding that had been installed to reduce worker dose when the facility operated now impeded efforts to remove the residue. Ultimately, a dose of 26 man-rem was acquired over a six-month period to remove this source; however, no individual worker exceeded the 1.5 rem per year management exposure goal. In changing the planned first two steps of the D\&D sequence, some of the noncontaminated equipment in the room became contaminated. This increased the amount of alpha contaminated waste generated; however, it prevented a higher total integrated personnel radiation exposure for the project. Direct management participation should be planned for ALARA evaluations in future D\&D activities.

The amount of time the D\&D worker spends on the job is not only related to task planning, but also to the amount and kind of protective equipment required for the task. Personnel working in highly contaminated areas, requiring plastic suits with breathing air, may perform up to three hours work per entry into the contaminated area. This is considered a safe limit for physical exertion within such confinement. During a 10-hour shift, two 3 hour entries are readily accomplished, whereas an 8-hour shift will acconmodate two 1.5-hour entries. Therefore, one 10-hour shift was found to accomplish the same amount of work as two 8-hour shifts. Preplan meetings to review the specific task and emergency procedures reduce time and cost, and should precede every entry into the contaminated work area. Obviously, good communication is essential to reduce the hazard and duration of the D\&D tasks.

An important operation in D\&D is the removal of items from a contaminated to a clean environment without transferring contamination to the clean area. Airborne contamination must be minimized. In the HB-Line, surface 
contamination at tens of millions of disintegrations per second was not uncommon. Ventilation control and containment ar'; the chief tools in preventing the spread of alpha contamination. The sequence of equipment removal from a plutonium facility should result in the least dispersion of contamination. One of the first steps in D\&D is setting up a series of staging areas for packaging and removing process equipment, tanks, gloveboxes, and waste. Objects are removed from the work area by employing a series of large scale "bag-out" steps. Successive layers of plastic or paper are applied to ensure a minimum of contamination on the outer package.

For packaging sharp or irregularly shaped objects, use of a standardized box improved safety, minimized void space, and provided a uniform shape for waste handling. A modular approach to packaging was adopted using standard box sizes. The primary waste box size is 3-, $\times 3-, \times 3-\mathrm{ft}$, and two of these primary boxes can be fitted into an intermediate sized 5-, $x 5-, \times 6-\mathrm{ft}$ box. Six of the intermediate sized boxes can be placed in the largest 12-, x18-, x6-ft waste storage container. A weight limitation of 1000 to 2000 pounds handling capacity within the facility determined the size reduction required and the box size employed for the removal of equipment and waste.

Staffing

This project benefited at its inception from having trained personnel familiar with the operating facility to initiate the D\&D. However, because of the prolonged period that has elapsed during the project, replacement personnel have had to be trained to an equally high level of competence. The D\&D activities are much less routine than repetitive production operations. This means the workers must have a high degree of confidence in themselves and their coworkers to respond quickly and correctly when unplanned situations occur. There were occurrences in which one or more workers, in plastic suits in highly contaminated environments, had their breathing air suddenly interrupted. It took less than a minute for their coworkers to get them out of three layers of protective plastic suits and out of the facility, uncontaminated. To ensure this performance, the D\&D project started with an experienced crew, and then maintained a high standard of replacement worker competence through training and detailed pre-entry review of tasks and emergency procedures.

Since this project is labor intensive, the work planning method used was to project staffing requirements and estimate the time for task completion. During the first years of the project, work was scheduled on a single 8 -hr shift per day, and total staffing averaged about $\mathbf{4 0}$ to 50 full time employees. The labor breakdown was as follows: $40 \%$ D\&D workers, $30 \%$ construction workers, $20 \%$ management, and $10 \%$ health protection and technical support. Later, the work schedule was expanded to a 12-hr shift per day to increase entry time per shift. Two 12 -hr shifts per day were scheduled to speed the work to meet the incoming facility construction schedule. Currently, a single 10 -hr shift day is used on the remainder of the facility where there is no schedule for future occupancy. Typical staffing for the last 6 months is shown in Table 2.

Demonstrated D\&D Techniques

During the dismantlement phases, the plasma arc torch was used for speedy size reduction of process cabinets, heavy construction items, and equipment that would not fit into standard size boxes. Ventilation control was crucial in minimizing the spread of alpha contamination in the working areas. Methods 
for successfully removing both personnel and materials, including waste from very highly contaminated areas were demonstrated. The Kelly decontamination system, using superheated water to cliemically and mechanically remove contamination, was found to successfully decontaminate large concrete areas. A wide variety of chemicals were used in conjunction with the Kelly System to enhance the efficiency of decontamination. A Bead Blaster was found to quickly remove deeply penetrated contamination from large areas of concrete floor. New decontamination materials were also tested, such as "tacky" wipes, that resulted in good decontamination factors on smooth surfaces.

\section{Waste Generation}

A key consideration in facility D\&D is the method for disposing of the contaminated residues. The solid waste is made up of the facility contents and the job-control waste generated in its removal. An estimate of the original contents (cabinets, ducts, conduit, and equipment) of Scrap Recovery and the Neptuniurn Line was $1957 \mathrm{cu} f$ of cabinets, gloveboxes, ductwork, and conduits, weighing 45,010 pounds. Figures 2 through 6 show photographs of the facility before, during, and after equipment removal. Approximately $213,000 \mathrm{cu} \mathrm{ft}$ of solid waste resulted from the D\&D of these facilities.

The dimensions of the disposal containers dictate how much in situ size reduction is necessary. At SRS, packaged waste is accepted for long term storage in a variety of containers, from polyethylene lined 55-gal steel drums to 45-, 90-, and 1500-cu ft steel boxes. These standard containers were used in conjunction with the modular wasteboxes developed by the project. Glovebox segments 2-, x3-, x4-ft were packaged intact; however, large process cabinets were cut into 2- to 3 -ft segments by plasma arc. Items such as ducts were cut into flat sections and boxed. The packaged waste was transported to the SRS Solid Waste Disposal Facility (SWDF) for interim pad storage to await final treatment and packaging for disposal.

Three types of solid waste are generated in the D\&D of plutonium facilities: TRU waste containing transuranic isotopes of greater than 20 year half-life at concentrations more than 100 nanocuries per gram $(\mathrm{nCi} / \mathrm{g})$ alpha, low-level waste (LLW) containing less than $100 \mathrm{nCi} / \mathrm{g}$ alpha, and mixed waste that may be either TRU or LLW combined with a hazardous material. Eventually, stored TRU waste will be processed and packaged in an acceptable form for eventual disposal in the Waste Isolation Pilot Plant (WIPP). Current plans are for indefinite storage of the LLW and Mixed waste in qualified nearsurface vaults in the SWDF at SRS.

Solid waste generated during the D\&D effort is summarized below in terms of the empty facility floor area. This basis was chosen because most plutonium facilities require a comparable operating and maintenance floor area to operate and maintain the enclosed processes cabinet areas. Another way to express $D \& D$ waste generation is to divide the total waste volume from $D \& D$ by the original equipment volume, which results, in this case, in a factor of 109 increase. 


\begin{tabular}{lcc} 
Waste Type & Volume, cu ft & Relative Volume* \\
\cline { 2 - 3 } & 108,000 & 22 \\
TRU & 104,550 & 21 \\
LWW & 450 & \\
Mixed Waste & & \\
* cu ft per square foot of facility floor area (5000 sq $\mathrm{ft})$
\end{tabular}

The amount of liquid decontamination waste generated to date is unavailable. The contaminated wash water was pumped to the adjacent canyon for evaporation and transfer to the waste tanks. This information is now being documented for future reference.

\section{Conclusions}

Cost and Duration

Lessons Learned
Excluding the eventual TRU waste processing cost, the project has cost about 12.5 million dollars to completely D\&D approximately 5000 square feet of floor area of the plutonium facility, or $\$ 2500$ per square foot of plutonium facility. Although the elapsed time for the cleanup was 9 years, the effort was intermittent and is estimated to have required about five years of continuous effort.

Risks to worker safety are much greater for D\&D than for routine production activities because dismantlement changes the physical characteristics of the facility. It is desirable to begin with a core of competent personnel familiar with the facility; however, because of the prolonged duration of these projects, constant training of replacement workers is necessary to maintain the required level of safety and efficiency.

In planning D\&D where there is residual radiation, one must decide how ALARA goals are best served. A higher dose to a few workers during a short time for source removal can prevent higher total doses to many workers over an extended period of time.

Adequate ventilation must be provided to control the spread of contamination. During dismantling activities, ventilation must be adjusted to maintain airflow toward the more contaminated areas as the room shape changes from wall and barrier removal. As the project evolves, a graded approach to DOE Order compliance may be necessary to adapt previously installed automated fire, criticality, and contamination alarm systems to meet the altered needs of the decontaminated state of the facility.

D\&D schedules should make some provision for unanticipated delay. Apparently simple tasks may become quite complex and time consuming. Design of most existing plutonium facilities was for efficiency of operation and not for ease of D\&D. Subsequent modifications made during operations for expedience may cause problems in the eventual D\&D. Even new plutonium facilities for Complex 21, although required to be designed for D\&D, might unintentionally be modified during operational life in ways that might present formidable D\&D challenges. 
Table 1. D\&D Planned Sequence

\section{PHASE I - Removal of all Non-Contaminated Equipment}

a. Flush all tanks, service piping, and sumps.

b. Physically trace and identify with tags or painted on labels all lines and service equipment not visibly identified.

c. Remove all non-contaminated equipment.

PHASE II - Cabinet Cleaning, Removal of Interior Equipment, Piping, etc.

a. Replace cabinet gloves, cabinet HEPA filters, and bag ports.

b. Remove all waste.

c. Sweep cabinets as clean as possible. Sample sweepings and analyze sweepings for product content, package sweepings for disposal or recovery based on analysis, and bag out of cabinets.

d. Disassemble all equipment inside the cabinets; package and bag out of cabinets.

e. Clean cabinet interior to an acceptable limit established by the D\&D team. Paint cabinet interior to fix loose contamination.

\section{PHASE III - Cabinet Removal}

a. Disconnect and blank off all external services except for ventilation. At this time, these services are cut back only to the extent necessary to facilitate removal of the gloveboxes or equipment. Because some of these service lines are radioactively contaminated internally, a contamination control technique such as fixation, bagging, or use of a temporary enclosure is required at each severance point .

b. Clean the stripped glovebox again, and coat the internal area of the glovebox with clear coat which sets up to secure any residual contamination within the glovebox. The ventilation supply and exhaust lines are disconnected and blanked off.

c. Separate each glovebox from the adjoining gloveboxes, section if larger than the waste package, and package according to regulations for shipment.

d. Remove the remaining services and support back to their point of origin after the gloveboxes have been removed.

\section{PHASE IV - General Decontamination and Refurbishment}

a. Decontaminate the vacated area now to as low as economically practicable by removing a layer of material from walls, ceilings and floors if need be to complete the D\&D.

b. Reinstall minimum services and safety alarms. Paint and refinish walls and floors as necessary. 
Table 2. Current D\&D Project Manpower

\section{A. Operations Personnel}

16 Nonexempt D\&D Operators

7 Supervisors

1 Engineer

6 Health Protection Inspectors

2.5 HP Inspector-Supervisors

$\begin{array}{ll}\text { Engineering } & 85 \text { man-hours/month } \\ \text { Technical Support } & 55 \text { man-hours/month } \\ \text { Project Controls } & 85 \text { man-hours/month } \\ \text { Analytical Lab } & 12 \text { man-hours/month }\end{array}$

\section{B. Construction Personnel}

30 Construction-Manual

4 Construction Non-Manual

Project Management

Project Controls

40 man-hours/month

Design Engineer

40 man-hours/month

40 man-hours/month 


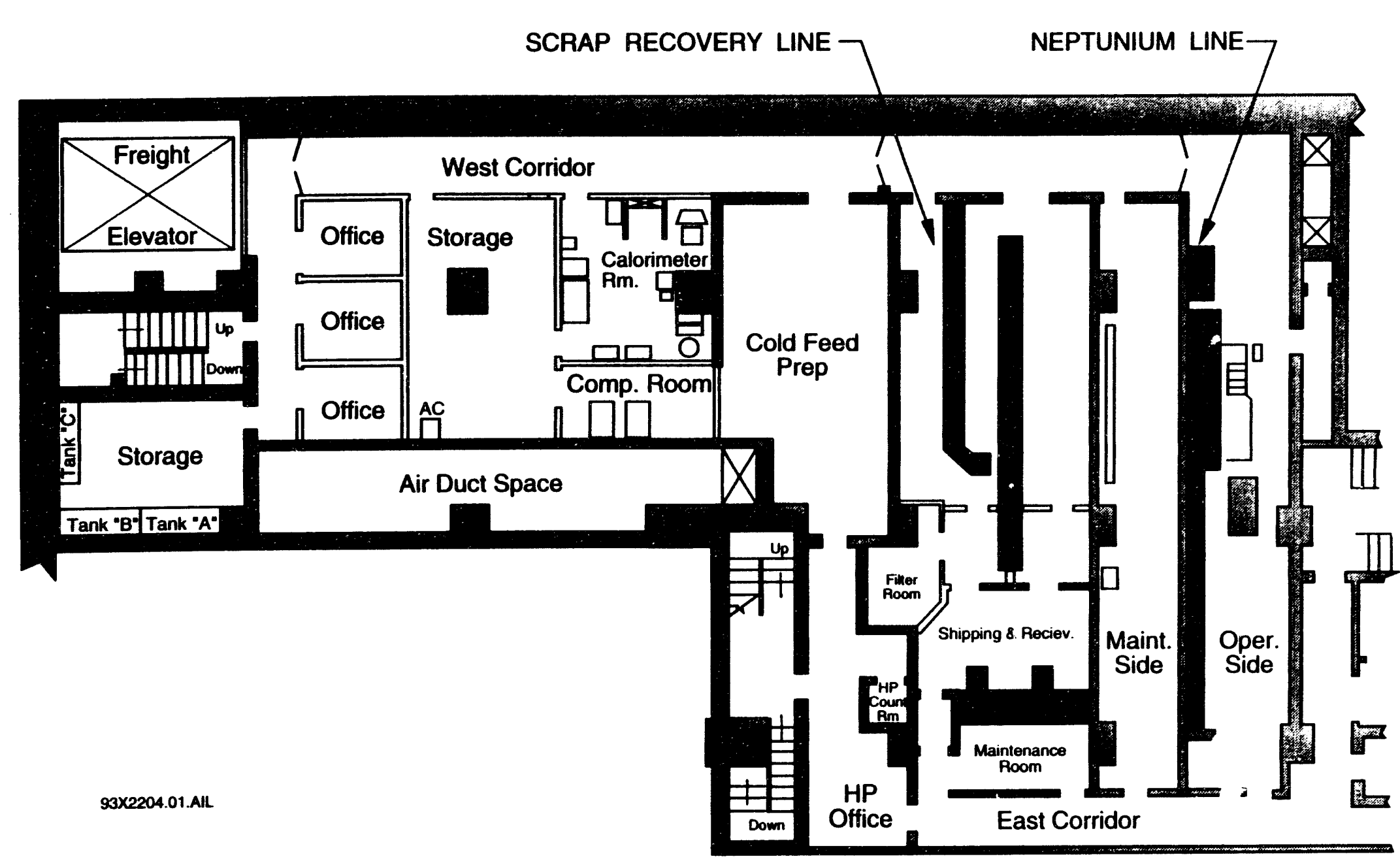

Figure 1. Floor Plan of Cleaned-up Half of Pu-238 Facility Before D\&D (Interior walls have subsequently been removed.) 


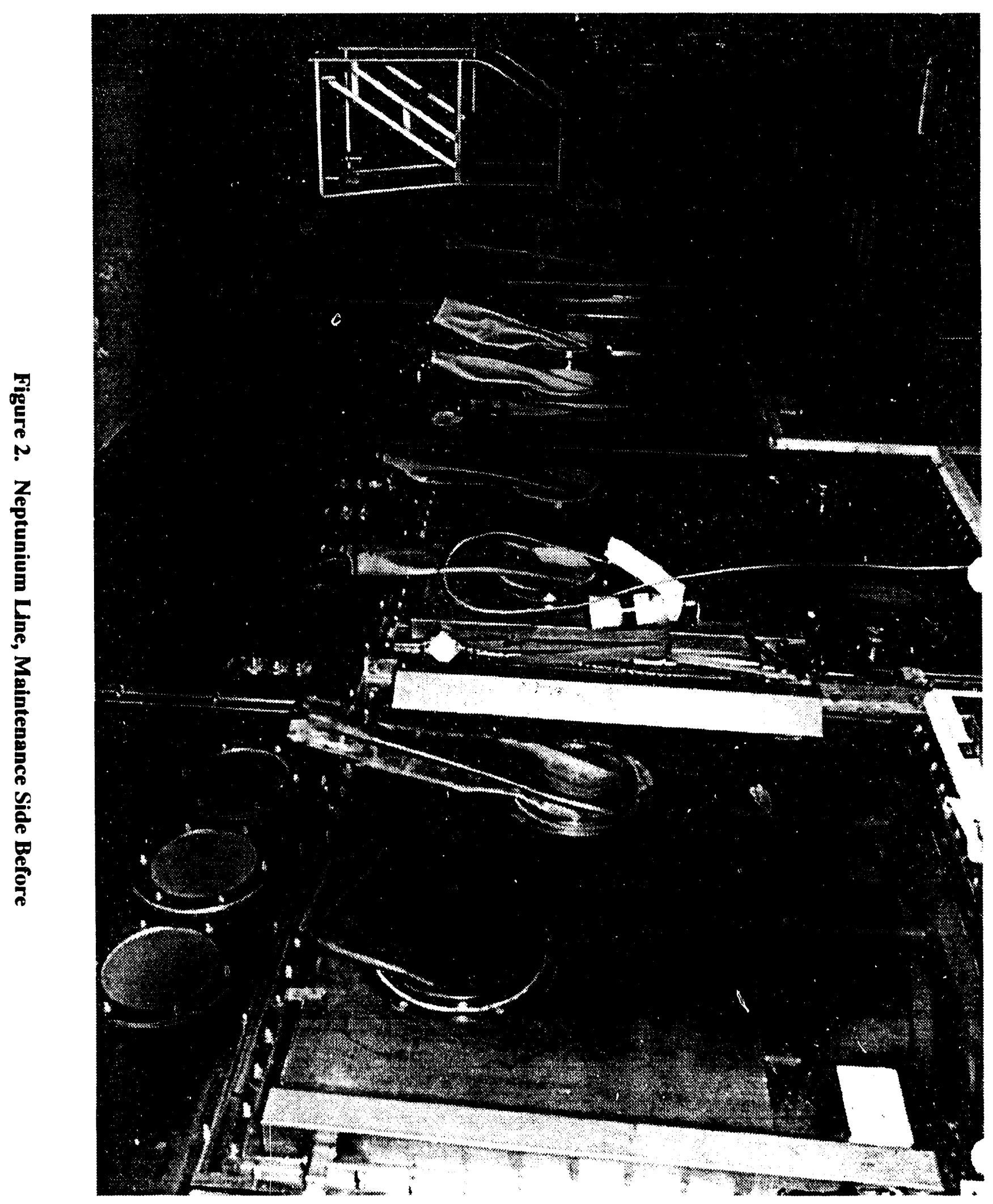




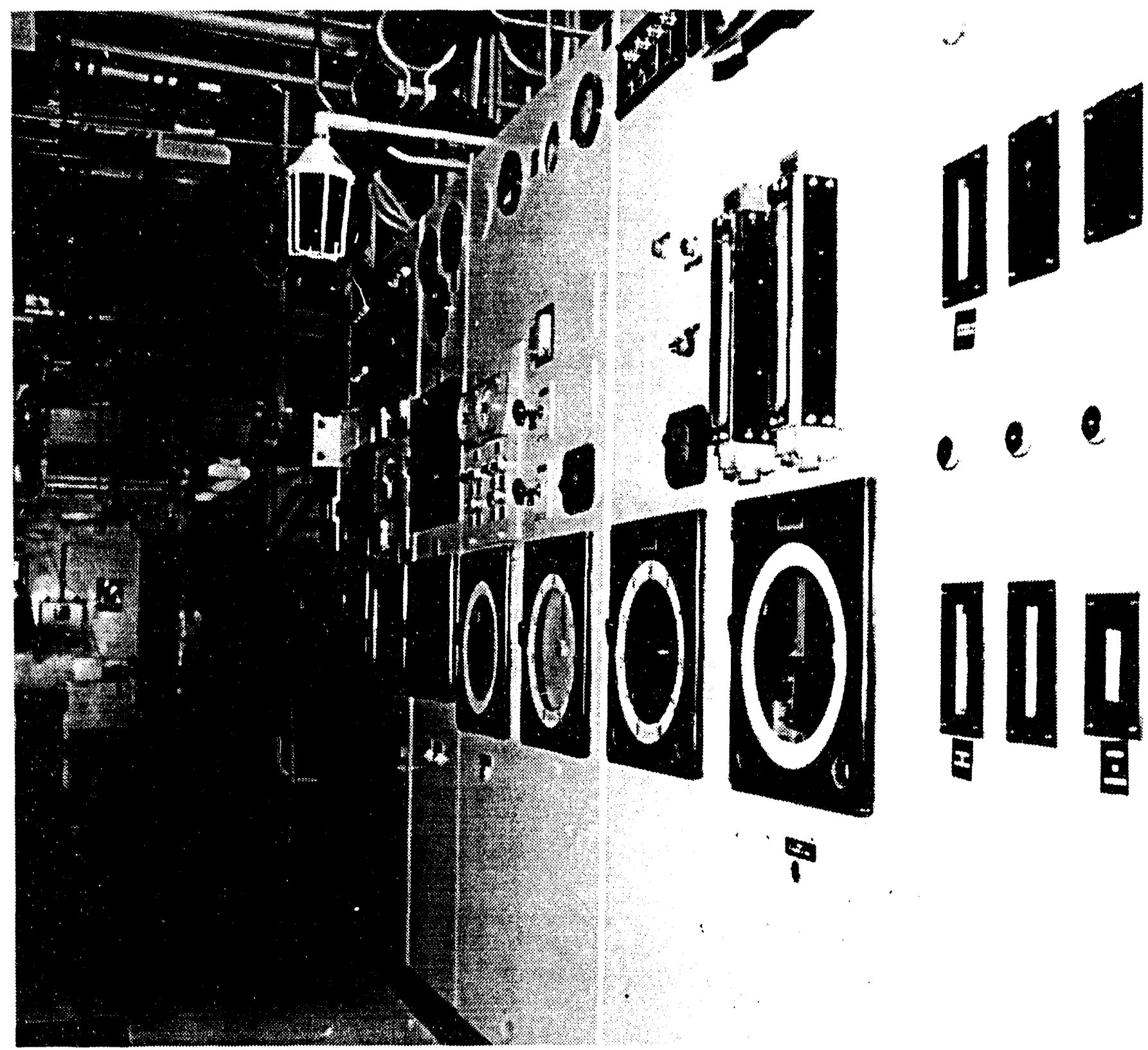

Figure 3. Instrument Panel and Orerhead Service Lines Maintenance Side Neptunium Line Before 


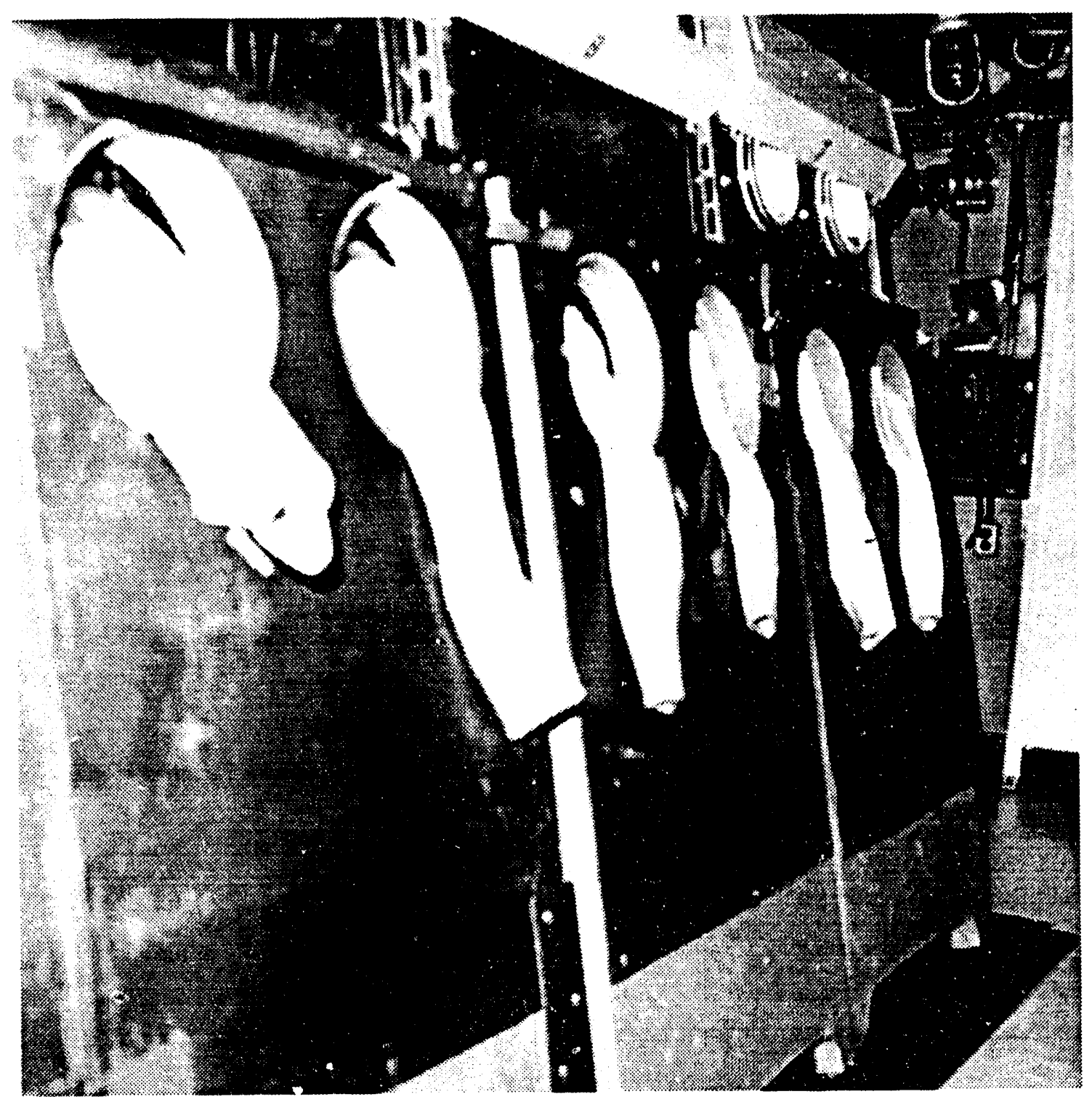

Figure 4. Shielded Cabinets, Neptunium Line Operations Side Before 


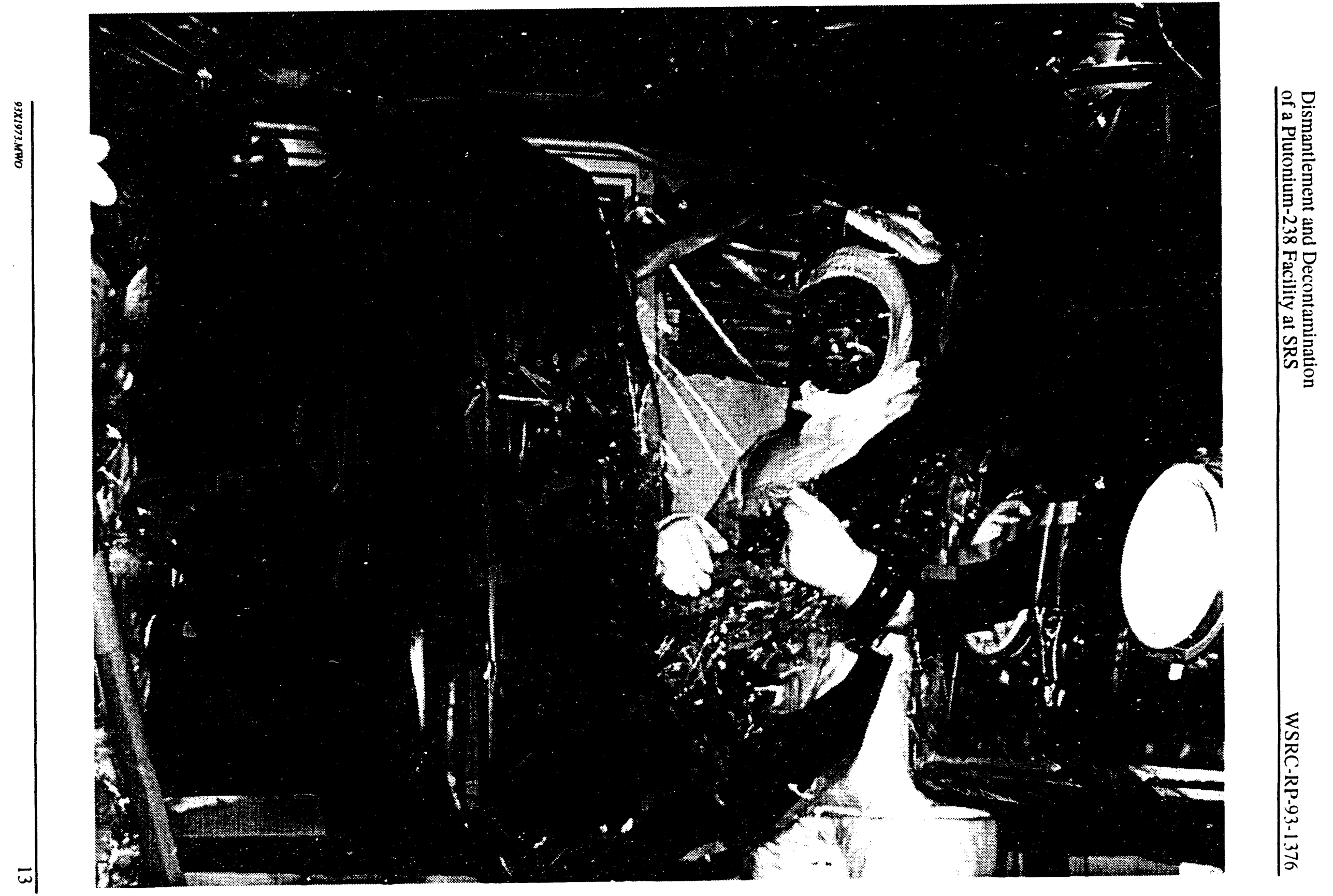

Figure 5. Scrap Recovery Glovebox Dismantlement and Removal 


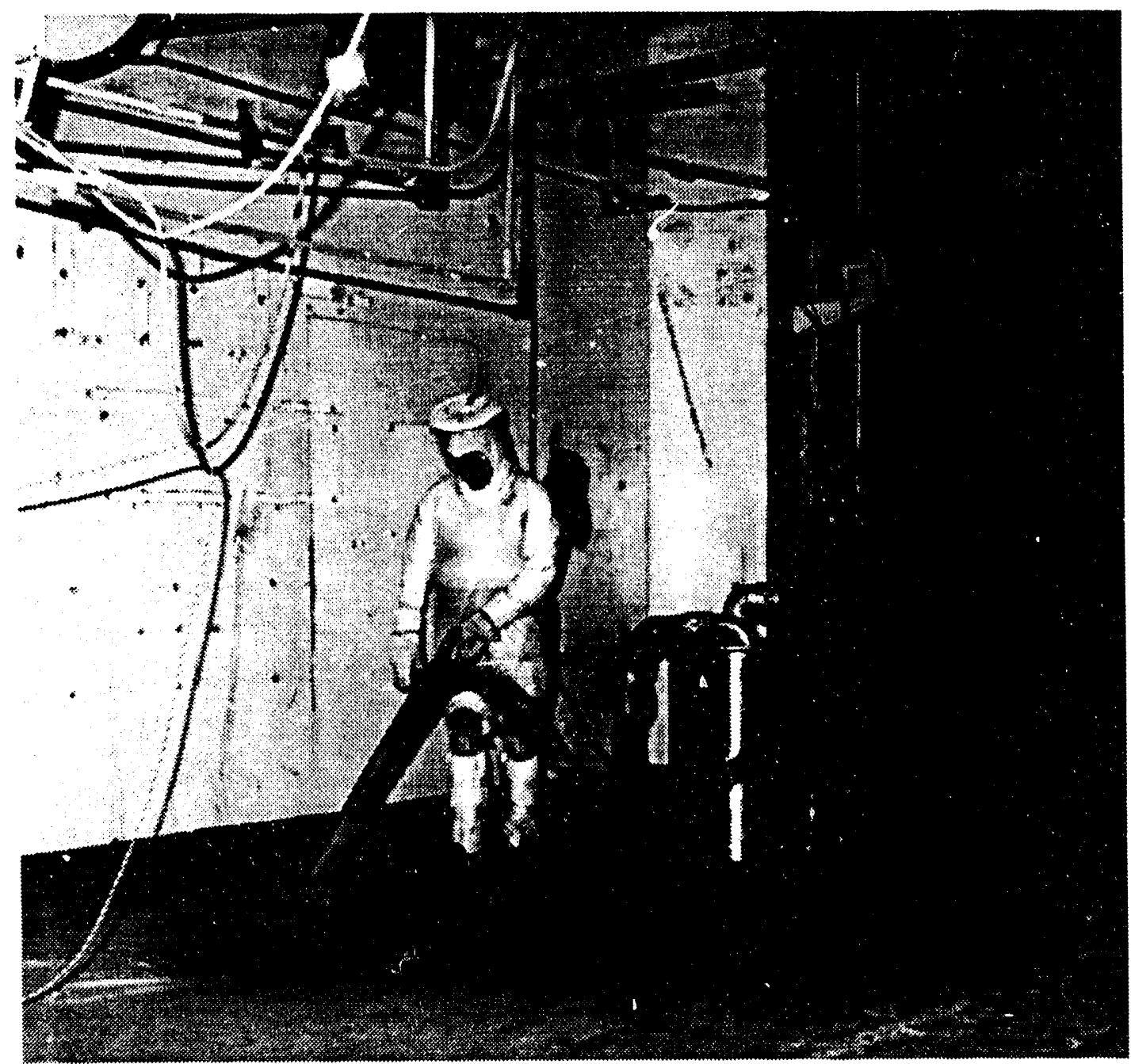

Figure 6. Room Cleanup with Kelly System after Cabinet and Equipment Removal 
This page intentionally left blank. 


\section{DISTRIBUTION:}

R. Maher, 703-A

M. J. Sujka, 703-A

J. G. McKibbin, 704-2H

C. G. Spencer, 704-2H

D. B. Rose, 704-2H

J. P. Duane, 704-F

N. C. Boyter, 735-B

C. B. Jones, 735-B

W. E. Austin, CCC-4

H. P. Olson, CCC-4

G. H. Street, 773-41A

T. H. Gould, 773-41A

R. E. Meadors, 773-A

R. H. Smith, Jr., 704-2H

H. E. Hootman, 773-41A

B. S. Strack, 703-43A

C. W. Tope, 703-43A (2)

PSA File, 773-41A

Records Administration, 773-52A (5) 

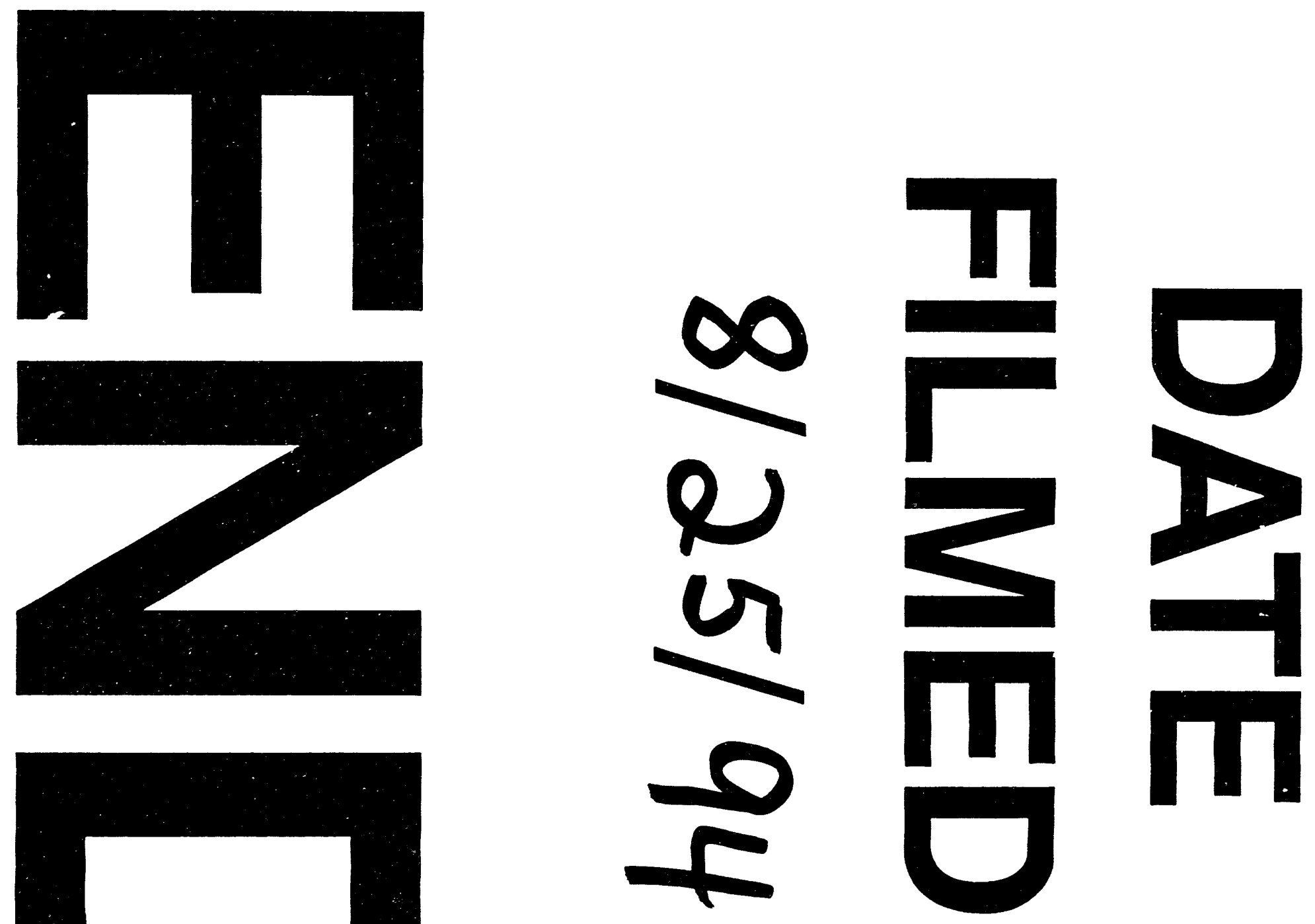


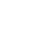

